\title{
Optical density of bone repair after implantation of homogenous demineralized dentin matrix in diabetic rabbits
}

\begin{abstract}
Mônica Fernandes Gomes ${ }^{(a)}$ Maria Fernanda de Souza Setúbal Destro(b)

Éfani Caroline de Freitas Banzi(c)

Evanice Menezes Marçal Vieira ${ }^{(d)}$

Aline Rose Cantarelli Morosolli(e) Maria das Graças Vilela Goulart ${ }^{(f)}$
\end{abstract}

\footnotetext{
(a) PhD, Professor and Chairperson, Special Health Care Needs Association (ASPE); (c)DDS, Resident, Special Health Care Needs Association (ASPE); (f)PhD, Associate Researcher - Bioscience Center for Special Health Care Needs (CEBAPE), School of Dentistry of São José dos Campos, São Paulo State University (UNESP), São José dos Campos, SP, Brazil.

(b)DDS, Post-doctoral fellow, Department of Oral Diagnosis, Piracicaba Dental School, State University of Campinas (UNICAMP), Piracicaba, SP, Brazil.

(d) DDS, MS, Professor of Pathology, University of Cuiabá, Cuiabá, MT, Brazil.

(e) Stomatology Clinic, School of Dentistry, Pontifical Catholic University of Rio Grande do Sul, Porto Alegre, RS, Brazil.
}

\footnotetext{
Corresponding author: Mônica Fernandes Gomes Av. José Francisco Longo, 777

São José dos Campos - SP - Brazil

E-mail:mfgomes@fosjc.unesp.br
}

Received for publication on Dec 01, 2006 Accepted for publication on May 23, 2007

\begin{abstract}
This research evaluated the bone repair process after implantation of homogenous demineralized dentin matrix (HDDM) in surgical defects in the parietal bone of rabbits with alloxan-induced diabetes, using a polytetrafluorethylene (PTFe) barrier for guided bone regeneration. Thirty-six rabbits were used and divided into four groups: control $(\mathrm{C}$, $\mathrm{n}=12$ ), diabetic ( $\mathrm{D}, \mathrm{n}=12$, left parietal bone), diabetic with PTFe (DPTFe, same 12 rabbits, right parietal bone), and diabetic with PTFe associated to HDDM (D-PTFe+HDDM, $n=12$ ). Bone defects were created in the parietal bone of the rabbits and the experimental treatments were performed, where applicable. The rabbits were sacrificed after 15, 30, 60 and 90 days. The bone defects were examined radiographically and by optical density (ANOVA and Tukey test, $\mathrm{p}<.05$ ). The radiographic findings showed that the D-PTFe+HDDM group presented greater radiopacity and better trabecular bone arrangement when compared to that of the C, D and D-PTFe groups. The statistical analysis showed significant differences in the optical density of the newly formed bone among the studied groups. It was possible to conclude that HDDM was biocompatible in diabetic rabbits.
\end{abstract}

Descriptors: Dentin; Bone regeneration; Guided tissue regeneration; Bone density; Diabetes mellitus. 


\section{Introduction}

Recent studies have shown that homogeneous demineralized dentin matrix (HDDM) slices stimulate new bone trabeculae formation, are incorporated into the surrounding bone tissue and are resorbed during the bone remodeling process. ${ }^{1-4}$

Diabetes mellitus is included in a group of metabolic diseases that are characterized by hyperglycemia. Diabetes mellitus has been related to long-term increase in blood glucose concentration. Glucose metabolites are formed after many cell processes in the tissues. One class of irreversible molecules formed has been termed advanced glycosylation end-products (AGEs). AGEs cause qualitative and quantitative changes in extracellular matrix components such as collagen, proteoglycans, laminin, and vitronectin. ${ }^{5}$ These changes in the extracellular matrix cause specific alterations in bone formation and bone remodeling. Bone formation and bone mineral homeostasis have been shown to be reduced in experimental diabetic animals. Osseous turnover has also been shown to be depressed as measured by a decreased percentage of osteoclasts, osteoblasts, and osteoid formation, as well as a decrease in osteocalcin synthesis. ${ }^{6-8}$

The aim of this work was to evaluate the dynamic process of bone repair after HDDM implantation in surgical bone defects created in the parietal bones of diabetic rabbits and occluded with polytetrafluorethylene (PTFE) barrier.

\section{Material and Methods}

Thirty-six New Zealand adult rabbits with an average weight of $3.5 \mathrm{~kg}$ were divided into 4 groups: control (C), diabetic (D), diabetic with PTFe barrier (D-PTFe) and diabetic with PTFe barrier associated to HDDM (D-PTFe+HDDM). All animals received human care according to the National Research Council's criteria and the study protocol had been previously approved by the Committee for Animal Use, School of Dentistry of São José dos Campos.

Diabetes was induced in rabbits by a single intravenous administration of alloxan monohydrate in the ear vein (dose $90 \mathrm{mg} / \mathrm{kg}$ ) (Sigma Aldrich Chemical, Saint Louis, MO, USA). In this study, a blood glucose level greater than $200 \mathrm{mg} / \mathrm{dL}$ indicated hyperglycemia. NPH Human Insulin (Humulin ${ }^{\circledR}$-100,
Eli Lilly do Brasil Ltda., São Paulo, SP, Brazil), and Regular Human Insulin (Biohulin ${ }^{\circledR}$ R-100, BioBRÁS S.A., Belo Horizonte, MG, Brazil) were administered subcutaneously to the animals daily to maintain a stable serum glucose level between $200 \mathrm{mg} / \mathrm{dL}$ and $350 \mathrm{mg} / \mathrm{dL}$. The blood glucose level was monitored three times a day until sacrifice of all the animals.

HDDM was obtained by extraction of the central incisor of the rabbits in the control group and then prepared in slices, according to Gomes et al. ${ }^{3,4}$ (2001, 2002) technique. The pulp tissue was totally removed by the apical foramina and the roots were scaled. After being washed with sterile physiologic serum at $2{ }^{\circ} \mathrm{C}$, the teeth were immersed in a $0.6 \mathrm{~N}$ hydrochloric acid solution at $2^{\circ} \mathrm{C}$, until complete demineralization. The specimens were then washed during 3 hours in distilled water under constant agitation, for total acid removal. The HDDM was cut into slices of approximately $8 \mu \mathrm{m}$ in thickness with the aid of a freezing microtome (Model CTD, International-Harris Cryostat, International Equipment Company, Needham heights, MA, USA). These slices were immersed in a special box filled with ethyl alcohol $70 \%$ gentamicin ( $5 \mathrm{ml}$ of alcohol per $0.2 \mathrm{ml}$ of gentamicin) and stored at $2^{\circ} \mathrm{C}$ until the time of implantation.

\section{Treatment protocol}

The animals were anesthetized intramuscularly with $0.1 \mathrm{mg} / \mathrm{dL}$ of Rompum (Bayer, São Paulo, SP, Brazil), a pre-anesthetic solution, and $0.25 \mathrm{mg} / \mathrm{dL}$ of Ketalar (Holliday-Scott, São Paulo, SP, Brazil). An incision was made along the median sagittal plane of the head, followed by muscular dissection by planes, with incision of the periosteum. Subsequently, a surgical bone defect was created in each parietal bone, with the aid of an $8.0 \mathrm{~mm}$ diameter trephine, and irrigated with $0.9 \%$ sterile saline solution. The bone defect had a circular form, with its depth equal to the thickness of the removed cortical bone. In the D$\mathrm{PTFe}+\mathrm{HDDM}$ group, a PTFe barrier was positioned on the floor of the bone defect and HDDM was placed in slices, internally and peripherally to the same bone defect. The external surface of the bone defect was completely recovered by PTFe barrier. In the D-PTFe group, PTFe barrier was placed on the floor and on the surface of the surgical bone defect. 
In the control and diabetic groups the bone defects were naturally filled with blood clot. Subsequently, the periosteum and muscle were sutured, as well as the skin. The animals were treated with an intramuscular injection of benzylpenicillin (24.000 UI/ $\mathrm{kg})$, streptomycin $(10 \mathrm{mg} / \mathrm{kg})$ and dihydrostreptomycin $(10 \mathrm{mg} / \mathrm{kg}) \quad$ (Pentabiótico ${ }^{\circledR}$; Fort Dodge Saúde Animal, São Paulo, SP, Brazil) after surgery and with $2.8 \mathrm{mg} / \mathrm{kg}$ of Celecoxib, (Celebra ${ }^{\circledR}$, Pfizer Pharmacia, São Paulo, SP, Brazil) during 5 days after surgery. Fifteen, 30, 60 and 90 days after surgery, 3 animals of each group were sacrificed. The bone containing the surgical defect was removed in block, fixed in $10 \%$ formalin during 72 hours, and submitted to digital radiographic examination.

\section{Optical density and statistical analysis}

To obtain digital radiographic images of the specimens, a sensor type image plate (Charge-Coupled Device, Trophy Radiologie, Vincennes, France) was utilized and the radiographs were exposed at a 40 $\mathrm{cm}$ ffd (fixed focal distance), $7 \mathrm{mAs}$, and $65 \mathrm{kVp}$. The sensor plate images were read by the software VixWin 1.9 (Gendex Dental System, Dentsply International, Chicago, IL, USA) and these images were transferred to a computer according to bone density features. The measurements of these digital images were performed by another software (Kodak, Aldus Photo Styler 2.0) which enabled mensuration of 256 grayscale levels. The optical density results were submitted to analysis of variance (ANOVA) and the Tukey test. The level of significance used was $\mathrm{p}<0.05$.
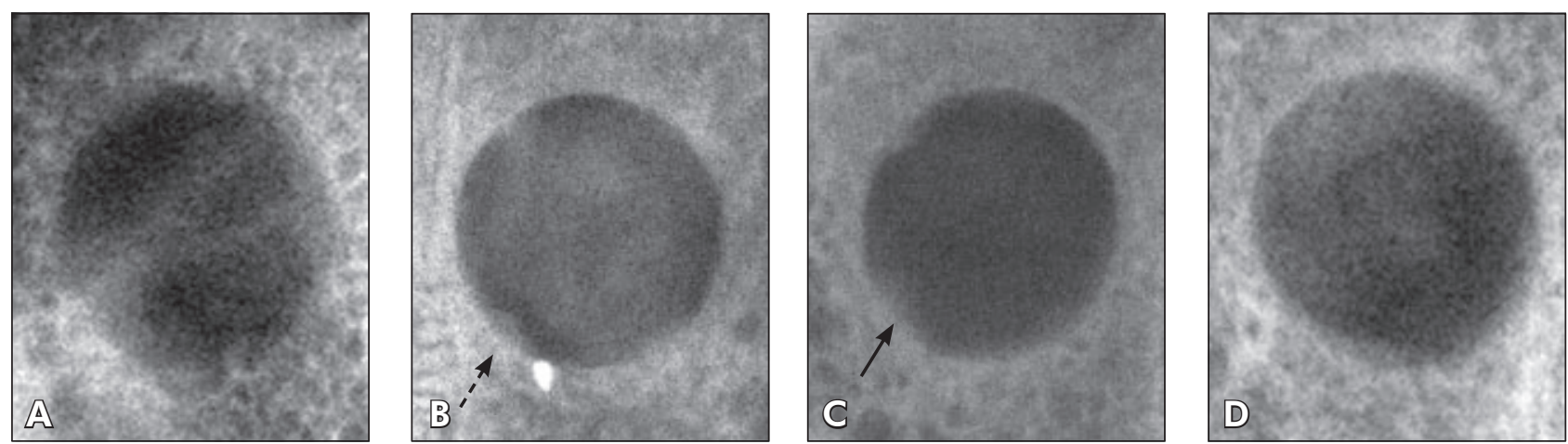

Figure 1 - Digital radiographic images of bone defect in the parietal bone of rabbit taken at 15 days: (A) control group; (B) diabetic group presenting radiopaque areas next to the defect walls (dotted arrow); (C) diabetic-PTFe group presenting extensive, homogeneous and radiopaque areas (continuous arrow); (D) diabetic-PTFe+ HDDM group. 
poorly expressed, with imprecise and irregular limits. It was more radiopaque in the peripheral region than in the central region of the surgical defect. This radiopacity was similar to that of normal bone. In the diabetic-PTFe group + HDDM, the defect presented a radiopaque image, with less intensity in comparison to that of the surrounding normal bone. These images were homogeneous in the periphery and heterogeneous in the central portion of the defect.

\section{Defect at 60 days}

In the control group, the bone defects were poorly defined. In some regions the limits of their walls could be observed, although there was evidence of increasing radiopacity in the limits of the surgical defect. In the diabetic group, the bone defect topography was well evidenced, but the pattern of the walls was imprecise and irregular when compared with those of the previous observation times. In the diabetic-PTFe group, the bone defect topography was poorly evidenced and its walls were imprecise and irregular. It was observed that there was a gradual increase of radiopacity in the central portion of the defect, but with less intensity when compared with the control group. In the diabetic-PTFe group + HDDM, a shadow was observed at the limits of the previous surgical defects; however, an homogeneous radiopacity was present in the other areas of the defect. The radiopacity of the central portion of the defect presented less intensity when compared with the normal surrounding bone tissue.
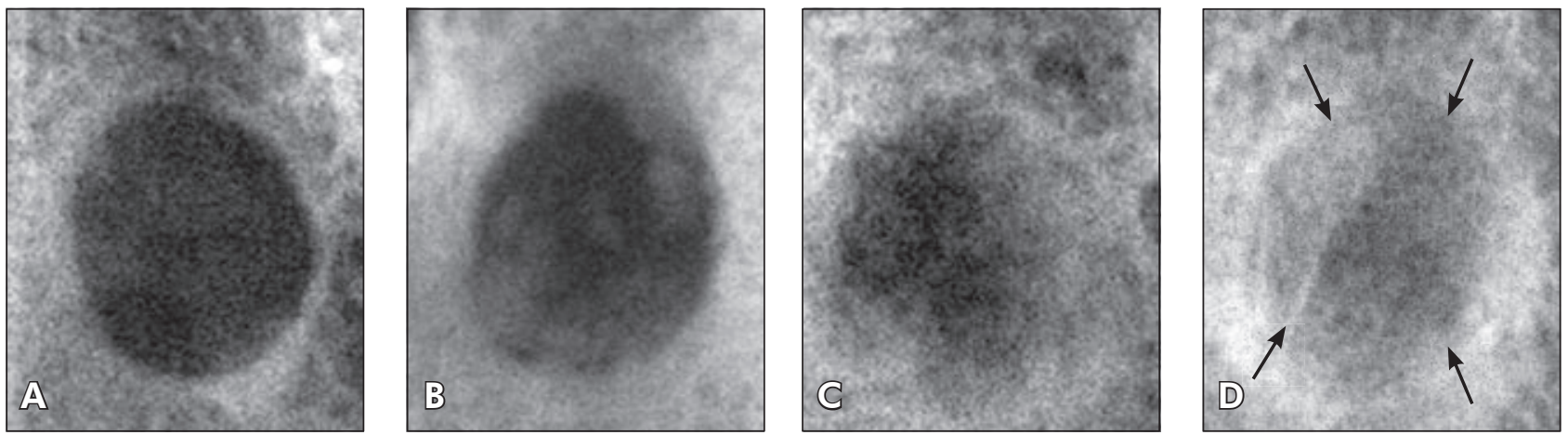

Figure 2 - Digital radiographic images of bone defect in the parietal bone of rabbit taken at 90 days: (A) control group; (B) diabetic group; (C) diabetic-PTFe group; (D) diabetic-PTFe+HDDM group where the region of the bone defect is replaced in most areas by a more intensively radiopaque image when compared to that of the normal surrounding bone (arrows). 
analysis. The optical density results were submitted to analysis of variance (ANOVA). The Tukey test was applied at a 5\% significant level. A uniformity in the progression of the optical density averages in the Diabetic, D-PTFe and D-PTFe+HDDM groups was not observed (Table 1). We observed that there was a discrete decrease in optical density at 30 and 60 days in the diabetic group, and at 60 days in the DPTFe group. However, the optical density averages in the D-PTFe+HDDM group showed the same radiographic features in all observation times of this study.

At 15 days, significant differences in optical density were observed between the C and D-PTFe+HDDM groups $(\mathrm{p}<0.05)$, the $\mathrm{D}$ and D-PTFe+HDDM groups, and the D-PTFe and D-PTFe+HDDM groups $(\mathrm{p}<0.01)$. At 30 and 60 days, the $\mathrm{D}$ and $\mathrm{D}-\mathrm{PTFe}+\mathrm{HDDM}$ groups presented statistically significant optical density differences $(\mathrm{p}<0.01)$. At 90 days, the $\mathrm{C}$ and D-PTFe+HDDM groups, the D and $\mathrm{D}-\mathrm{PTFe}+\mathrm{HDDM}$ groups, and the D-PTFe and DPTFe+HDDM groups also presented significant differences in relation to optical density $(\mathrm{p}<0.001)$.

\section{Discussion}

During our review of the literature, no work was found using HDDM in diabetic patients. It is known, however, that many chronic complications of Diabetes mellitus patients are related to changes in bone metabolism, since it may impair the bone repair process. ${ }^{5,9}$

In the last years, researchers have added growth factors to occlusive barriers such as insulin growth factor, growth factor related to platelets, and bone morphogenetic proteins, among others, ${ }^{4,10}$ to accelerate the bone repair process. Some authors reported the presence of these growth factors in bone matrix and dentin matrix, which can explain their osteoinductive activity. ${ }^{10-12}$

During all observation periods of the control group, an average optical density that increased gradually and progressively (Table 1) was observed. Moreover, it was noticed that the PTFe barrier promoted an osteoconduction property, which influenced bone growth positively. These findings were also observed by Abreu et al. ${ }^{1}$ (2004), Carvalho et al. ${ }^{2}$ (2004) and Gomes et al..$^{3,4}$ (2001, 2002). However, a noticeable fact in all the diabetic groups was the discrepant variation in mean optical density values, especially after the 30 - and 60-day periods, with an intense decrease in optical density. This fact could be explained by the occurrence of chronic complications in our experiment caused by constant hyperglycemia, which was often difficult to be controlled, even using daily human insulin.

In all periods, it was observed that the diabetic-PTFe+HDDM group presented a significant increase in average optical density when compared to the other groups studied (Table 1). After the 15day period, a not statistically significant decrease in optical density in the diabetic groups and in the diabetic-PTFe groups was observed when compared with the control group. At 90 days, the group treated with HDDM presented a significant increase in optical density when compared with the control, diabetic, and diabetic-PTFe groups $(\mathrm{p}<.001)$ (Table 1). Moreover, the radiopaque images in the region of the bone defects implanted with HDDM were radiographically more homogeneous in all of their extension and after every observation period, when compared to the other groups studied. These findings were also observed by Abreu et al. ${ }^{1}$ (2004).

Therefore, in the diabetic-PTFe+HDDM group,

\begin{tabular}{|c|c|c|c|c|c|}
\hline \multirow{5}{*}{$\begin{array}{r}\text { Table } 1 \text { - Optical } \\
\text { Density of newly formed } \\
\text { bone (Mean } \pm \text { SD). }\end{array}$} & \multicolumn{2}{|c|}{\begin{tabular}{c|c}
$\begin{array}{c}\text { Days after } \\
\text { surgery }\end{array}$ & Control \\
$(\mathrm{C}, \mathrm{n}=12)$
\end{tabular}} & $\begin{array}{c}\text { Diabetic } \\
(D, n=12)\end{array}$ & $\begin{array}{c}\text { Diabetic-PTFe } \\
(\mathrm{D}-\mathrm{PTFe}, \mathrm{n}=12)\end{array}$ & \multirow{2}{*}{$\begin{array}{c}\text { Diabetic-PTFe +HDDM } \\
(\mathrm{D}-\mathrm{PTFe}+\mathrm{HDDM}, \mathrm{n}=12) \\
71.70 \pm 16.50^{* *}\end{array}$} \\
\hline & 15 & $33.33 \pm 3.42^{*}$ & $27.70 \pm 1.30$ & $30.63 \pm 6.00$ & \\
\hline & 30 & $36.22 \pm 2.54$ & $21.52 \pm 1.61$ & $38.55 \pm 6.77$ & $62.64 \pm 16.51^{* *}$ \\
\hline & 60 & $45.67 \pm 8.36$ & $23.33 \pm 2.62$ & $31.85 \pm 3.55$ & $63.04 \pm 11.04^{* *}$ \\
\hline & 90 & $50.51 \pm 11.02$ & $40.89 \pm 6.24$ & $56.37 \pm 18.10$ & $103.60 \pm 24.86^{* * *}$ \\
\hline
\end{tabular}


there was biocompatibility of HDDM, considering its integration with the newly formed bone matrix during all observation periods and the absence of any bone tissue reaction image as suggested images of bone sequestrum, osteomyelitis or others. Moreover, it has been demonstrated that HDDM stimulates bone tissue osteopromotion precociously and significantly, contributing to a more favorable progression of the bone regeneration process. ${ }^{3,4,13}$

Many advantages of HDDM became evident in the present study, confirming the possibility of its application in clinical dentistry, especially in implantodontology and for intra-oral surgeries in Diabetes mellitus patients which, in general, present high risk of infection and an impaired bone repair process.

\section{Conclusion}

It was possible to conclude that homogenous demineralized dentin matrix (HDDM) was bio-

\section{References}

1. Abreu PP, Morosolli A, Araújo MM, Carvalho VAP, Gomes MF. Effects of autogenous demineralized dentin matrix on dental socket wound healing process in human. Braz Oral Res. 2004;18(Suppl):52.

2. Carvalho VAP, Tosello DO, Salgado MAC, Gomes MF. Histomorphometric analysis of homogenous demineralized dentin matrix as osteopromotive material in rabbit mandibules. Int J Oral Maxillofac Implants. 2004;19(5):679-86.

3. Gomes MF, Anjos MJS, Nogueira TO, Catanzaro-Guimarães SA. Autogenous demineralized dentin matrix for tissue engineering applications: radiographic and histomorphometric studies. Int J Oral Maxillofac Implants. 2002;17(4):488-97.

4. Gomes MF, Silva MJS, Nogueira TO, Catanzaro-Guimarães SA. Histologic evaluation of the osteoinductive property of autogenous demineralized dentin matrix on surgical bone defects in rabbit skulls using human amniotic membrane for guided bone regeneration. Int J Oral Maxillofac Implants. 2001;16(4):563-71.

5. Guyton AC, Hall JE. Insulin, Glucagon, and Diabetes mellitus. In: Guyton AC, Hall JE. Textbook of Medical Physiology. $11^{\text {th }}$ ed. Philadelphia: Elsevier; 2006. p. 827-40.

6. Fiorellini JP, Nevins ML, Norkin A, Weber HP, Karimbux NY. The effect of insulin therapy on osseointegration in a diabetic rat model. Clin Oral Implants Res. 1999;10(5):362-8.

7. Lu H, Kraut D, Gerstenfeld LC, Graves DT. Diabetes interferes with the bone formation by affecting the expression of compatible with newly formed bone in diabetic rabbits. HDDM stimulated an increase in bone defect radiopacity, suggesting new bone formation, and improving an osteopromotion property during the bone regeneration process. There were statistically significant differences $(\mathrm{p}<.001)$ among the diabetic-PTFe+HDDM, control, diabetic and diabeticPTFe groups.

\section{Acknowledgements}

This research was supported by the State of São Paulo Research Foundation (FAPESP; grant numbers 2003/06017-0 and 03/02018-2). The authors are grateful to Johnson \& Johnson MD\&D Latin America Manufacturing Company, Brazil, for the donation of surgical materials, OneTouch Ultra blood test strips and machine (LifeScan), and to Huber+Suhner Latin America for the financial support given to the Special Health Care Needs Association (ASPE).

transcription factors that regulate osteoblast differentiation. Endocrinology. 2003;144(1):346-52.

8. Nevins ML, Karimbux NY, Weber HP, Giannobile WV, Fiorellini JP. Wound healing around endosseous implants in experimental diabetes. Int J Oral Maxillofac Implants. 1998;13(5):620-9.

9. Claro FA, Lima JR, Salgado MAC, Gomes MF. Porous Polyethylene for tissue engineering applications in diabetic rats treated with calcitonin: histomorphometric analysis. Int J Oral Maxillofac Implants. 2005;20(2):211-9.

10. Catanzaro-Guimarães SA, Catanzaro Guimarães BP, Garcia $\mathrm{RB}$, Alle N. Osteogenic potential of autogenic demineralized dentin implanted in bony defects in dogs. Int J Oral Maxillofac Surg. 1986;15(2):160-9.

11. Bessho K, Tagawa T, Murata M. Purification of rabbit bone morphogenetic protein derived from bone, dentin, and wound tissue after tooth extraction. J Oral Maxillofac Surg. 1990;48(2):162-9.

12. Nakashima M. Induction of dentine in amputated pulp of dogs by recombinant human bone morphogenetic proteins- 2 and -4 with collagen matrix. Arch Oral Biol. 1994;39(12):1085-9.

13. Catanzaro-Guimarães SA. Possibility to reinforce bone repair with decalcified dentin matrix. In: Gesellschaft für orale Implantologie (ed.). Jahrbuch für Orale Implatologie. Berlin: Quintessenz; 1993.p. 33-4. 